\title{
Cerebral amyloid angiopathy: a long-term consequence of traumatic brain injury?
}

\author{
Niklas Marklund ${ }^{1}$ (D) \\ Received: 14 October 2016 / Accepted: 19 October 2016/Published online: 31 October 2016 \\ (C) Springer-Verlag Wien 2016
}

In this issue of Acta Neurochirurgica, Dr. Nakayama and coworkers present an interesting case report describing a 32year-old man who presented with lobar intracerebral hemorrhages where a tissue biopsy obtained at surgery confirmed the diagnosis of cerebral amyloid angiopathy (CAA). CAA is a consequence of $\beta$-amyloid deposition in the media and adventitia of small cerebral vessels, is predominately observed in elderly patients $>55$ years, and commonly leads to multiple lobar intracerebral hemorrhages as well as cognitive impairment [1]. In fact, this case in Acta is the youngest CAA patient ever reported and only the third confirmed CAA case in a patient less than 40 years old. The common denominator of each of these three young CAA cases is that they all had sustained a previous traumatic brain injury (TBI), in the case presented by Dr. Nakayama at a very young age. Although there should be much caution when interpreting a causative role for TBI in these rare CAA patients, this report adds to numerous others implying that TBI may have chronic, lifelong consequences. At the time of the initial traumatic impact, there is a loss of neuronal and glial cells and a complex secondary injury cascade is elicited [2]. Thus far, most TBI research has focused on these early post-injury events and a magnitude of therapies aiming at neuroprotection have been evaluated of which a subset reached the clinical trial stage. However, these compounds invariably failed to increase the rate of favorable outcomes in clinical TBI [3] and other treatment targets are needed. It is becoming increasingly clear that ongoing injury mechanisms contribute to a gradual worsening

Niklas Marklund

niklas.marklund@neuro.uu.se

1 Department of Neuroscience, Section of Neurosurgery, Uppsala University Hospital, 75185 Uppsala, Sweden of the initial brain injury and an increased risk of developing neurodegenerative disorders. The mortality following TBI is increased many years following the initial event [4] and posttraumatic epilepsy is another common life-long condition observed particularly in severe TBI patients [5]. In addition, some degree of chronic cognitive impairment is a feature of virtually every patient surviving severe TBI [6] and when using longitudinal radiological evaluations, a generalized and progressive brain atrophy can be observed post-TBI [7]. Finally, epidemiological evidence suggests that TBI is associated with an increased risk of Parkinson's disease, Lewy body accumulation, and an accelerated onset as well as a fourfold increase of risk of Alzheimer's disease (AD) [8, 9].

The mechanisms leading to progressive brain atrophy and increased risk of neurodegeneration is unclear at present. Autopsy studies as well as positron emission tomography (PET) evaluation in chronic TBI survivors up to many years following the injury have revealed an ongoing neuroinflammation, white matter degeneration, and aggregation of betaamyloid $(A \beta)$ peptides, one key pathological hallmark of $A D$ $[10,11]$. Although CAA and AD share similarities including a $\beta$-amyloid-based pathophysiology, CAA is a disease entity separate from $\mathrm{AD}$. Less than half of CAA patients have $\mathrm{AD}$ and $75 \%$ of $\mathrm{AD}$ patients have no or only mild CAA [1]. Thus, it is unclear if the risk increase of $\mathrm{AD}$ and the potential link to CAA following TBI share common mechanisms.

An additional hallmark finding of $\mathrm{AD}$ is the accumulation of tau in the form of neurofibrillary tangles (NFTs) and similarly, TBI appears to result in an increased and delayed deposition of tau and NFTs in patients surviving beyond the first post-injury months [12]. In addition, the predominant accumulation of tau over $A \beta$ is observed in chronic traumatic encephalopathy (CTE), which is mainly a tauopathy seen in selected individuals suffering repeated concussions during life [13]. 
The diagnosis of CAA in patients younger than 55 years old requires histological proof of amyloid deposition in the vascular wall. How these vascular changes may relate to TBI has not been established, although a blood-brain barrier disturbance is observed in up to $50 \%$ of patients many years after moderate-to-severe TBI [14]. Injury to the neurovascular system has been observed chronically both after moderate-to-severe TBI and following sports-related concussions, suggesting that cerebrovascular abnormalities may persist following TBI, which may be related to the vascular pathologies observed in the present CAA case $[15,16]$.

Another important aspect of TBI raised in the present case report is the potential contribution of a genetic susceptibility for delayed consequences post-TBI. Carriers of the apolipoprotein $\mathrm{E}$ (APOE) $\varepsilon 4$ allele have both an increased risk for $\mathrm{AD}$ development and a worse outcome following TBI. In contrast, the APOE $\varepsilon 2$ allele is a risk factor for CAA [17]. In only $2 / 6$ CAA patients $<55$ years old reported in the literature was the APOE status reported, both of whom were APOE $\varepsilon 3 / \varepsilon 3$. Although larger TBI cohorts are obviously needed for evaluating the role of genetic risk factors, the few cases presented by Dr. Nakayama do not support a dominating genetic role in the development of CAA following TBI.

All six of the young CAA patients $<55$ years old previously found in the literature were male. Again, the rarity of this disorder prohibits a definitive conclusion of a gender predisposition for developing long-term complications post-TBI. In previous reports on chronic long-term inflammation [11] as well as tau and $\mathrm{A} \beta$ accumulation post-TBI [18], the vast majority of included patients were males (83 and $90 \%$, respectively). In the largest study on CTE, 85 individuals with potential CTE were evaluated of which there was only one female. In this cohort, $80 \%$ of the examined individuals were diagnosed with CTE although the only included female athlete was not [19]. Males are overrepresented in most TBI case series and it remains to be established whether they are at increased risk for CAA and long-term neurodegeneration following TBI. This should be evaluated in future studies.

While the pharmacological attenuation of the initial injury cascade aiming for neuroprotection has to date been unsuccessful, the growing literature on the long-term sequelae of TBI suggests that that there may be an extended time window with a potential for developing novel treatments. Whether the persisting or progressive pathology observed both following severe TBI as well as in repetitive sports-related concussions share common mechanisms, also leading to an increased risk of CAA, remains to be established. However, a neurosurgeon encountering a patient with a neurodegenerative disorder should be aware of a possible TBI in the patient's past medical history. The case presented here by Dr. Nakayama et al. adds to the list of disorders potentially associated with a previous TBI.

\section{References}

1. Viswanathan A, Greenberg SM (2011) Cerebral amyloid angiopathy in the elderly. Ann Neurol 70:871-880

2. McGinn MJ, Povlishock JT (2016) Pathophysiology of traumatic brain injury. Neurosurg Clin N Am 27:397-407

3. Bragge P, Synnot A, Maas AI, Menon DK, Cooper DJ, Rosenfeld JV, Gruen RL (2016) A state-of-the-science overview of randomized controlled trials evaluating acute management of moderate-tosevere traumatic brain injury. J Neurotrauma 33:1461-1478

4. Fazel S, Wolf A, Pillas D, Lichtenstein P, Långström N (2014) Suicide, fatal injuries, and other causes of premature mortality in patients with traumatic brain injury: a 41-year Swedish population study. JAMA Psychiatry 71:326-333

5. Pitkanen A, Immonen R (2014) Epilepsy related to traumatic brain injury. Neurotherapeutics 11:286-296

6. Dikmen SS, Ross BL, Machamer JE, Temkin NR (1995) One year psychosocial outcome in head injury. J Int Neuropsychol Soc 1:67-77

7. Ding K, Marquez de la Plata C, Wang JY, Mumphrey M, Moore C, Harper C, Madden CJ, McColl R, Whittemore A, Devous MD, Diaz-Arrastia R (2008) Cerebral atrophy after traumatic white matter injury: correlation with acute neuroimaging and outcome. J Neurotrauma 25:1433-1440

8. Crane PK, Gibbons LE, Dams-O'Connor K, Trittschuh E, Leverenz JB, Keene CD, Sonnen J, Montine TJ, Bennett DA, Leurgans S, Schneider JA, Larson EB (2016) Association of traumatic brain injury with late-life neurodegenerative conditions and neuropathologic findings. JAMA Neurol 73:1062-1069

9. Johnson VE, Stewart W, Smith DH (2010) Traumatic brain injury and amyloid-beta pathology: a link to Alzheimer's disease? Nat Rev Neurosci 11:361-370

10. Scott G, Ramlackhansingh AF, Edison P, Hellyer P, Cole J, Veronese M, Leech R, Greenwood RJ, Turkheimer FE, Gentleman SM, Heckemann RA, Matthews PM, Brooks DJ, Sharp DJ (2016) Amyloid pathology and axonal injury after brain trauma. Neurology 86:821-828

11. Johnson VE, Stewart JE, Begbie FD, Trojanowski JQ, Smith DH, Stewart W (2013) Inflammation and white matter degeneration persist for years after a single traumatic brain injury. Brain 136:28-42

12. Tsitsopoulos PP, Marklund N (2013) Amyloid-beta peptides and tau protein as biomarkers in cerebrospinal and interstitial fluid following traumatic brain injury: a review of experimental and clinical studies. Front Neurol 4:79. doi:10.3389/fneur.2013.00079

13. Meehan W 3rd, Mannix R, Zafonte R, Pascual-Leone A (2015) Chronic traumatic encephalopathy and athletes. Neurology 85 : $1504-1511$

14. Hay JR, Johnson VE, Young AM, Smith DH, Stewart W (2015) Blood-brain barrier disruption is an early event that may persist for many years after traumatic brain injury in humans. J Neuropathol Exp Neurol 74:1147-1157

15. Kenney K, Amyot F, Haber M, Pronger A, Bogoslovsky T, Moore C, Diaz-Arrastia R (2016) Cerebral vascular injury in traumatic brain injury. Exp Neurol 275:353-366

16. Wang Y, Nelson LD, LaRoche AA, Pfaller AY, Nencka AS, Koch KM, McCrea MA (2016) Cerebral blood flow alterations in acute sport-related concussion. J Neurotrauma 33:1227-1236

17. Maiti TK, Konar S, Bir S, Kalakoti P, Bollam P, Nanda A (2015) Role of apolipoprotein $\mathrm{E}$ polymorphism as a prognostic marker in traumatic brain injury and neurodegenerative disease: a critical review. Neurosurg Focus 39, E3

18. Johnson VE, Stewart W, Smith DH (2012) Widespread tau and amyloid-beta pathology many years after a single traumatic brain injury in humans. Brain Pathol 22:142-149 
19. McKee AC, Stern RA, Nowinski CJ, Stein TD, Alvarez VE, Daneshvar DH, Lee HS, Wojtowicz SM, Hall G, Baugh CM, Riley DO, Kubilus CA, Cormier KA, Jacobs MA, Martin $\mathrm{BR}$, Abraham CR, Ikezu T, Reichard RR, Wolozin BL,
Budson AE, Goldstein LE, Kowall NW, Cantu RC (2013) The spectrum of disease in chronic traumatic encephalopathy. Brain 136:43-64 